\title{
Neonatal Ureaplasma parvum meningitis complicated with subdural hematoma: a case report and literature review
}

\author{
Canyang Zhan *iD, Lihua Chen and Lingling Hu
}

\begin{abstract}
Background: Neonatal meningitis is a severe infectious disease of the central nervous system with high morbidity and mortality. Ureaplasma parvum is extremely rare in neonatal central nervous system infection.

Case presentation: We herein report a case of U. parvum meningitis in a full-term neonate who presented with fever and seizure complicated with subdural hematoma. After hematoma evacuation, the seizure disappeared, though the fever remained. Cerebrospinal fluid (CSF) analysis showed inflammation with CSF pleocytosis (11351319 leukocytes/ $\mu$ l, mainly lymphocytes), elevated CSF protein levels (1.36-2.259 g/l) and decreased CSF glucose $(0.45-1.21 \mathrm{mmol} / \mathrm{l})$. However, no bacterial or viral pathogens in either CSF or blood were detected by routine culture or serology. Additionally, PCR for enteroviruses and herpes simplex virus was negative. Furthermore, the CSF findings did not improve with empirical antibiotics, and the baby experienced repeated fever. Thus, we performed metagenomic next-generation sequencing (mNGS) to identify the etiology of the infection. U. parvum was identified by mNGS in CSF samples and confirmed by culture incubation on mycoplasma identification medium. The patient's condition improved after treatment with erythromycin for approximately 5 weeks.
\end{abstract}

Conclusions: Considering the difficulty of etiological diagnosis in neonatal U. parvum meningitis, mNGS might offer a new strategy for diagnosing neurological infections.

Keywords: Neonate, Ureaplasma parvum, Meningitis, Subdural hematoma, Metagenomic next-generation sequencing $(\mathrm{mNGS})$

\section{Background}

Neonatal meningitis is a severe infection of the central nervous system (CNS) with high morbidity and mortality and can lead to serious neurological complications or long-term disabilities $[1,2]$. Ureaplasma spp., including Ureaplasma parvum (U. parvum) and Ureaplasma urealyticum ( $U$. urealyticum), are rare pathogens in neonatal CNS infection. It has been indicated that Ureaplasma spp. are associated with adverse neonatal outcomes, such as congenital pneumonia, bronchopulmonary dysplasia

\footnotetext{
* Correspondence: 6310005@zju.edu.cn

Departments of Neonatology, The Children's Hospital, Zhejiang University School of Medicine, National Clinical Research Center for Child Health, Hangzhou, China
}

and perinatal death $[3,4]$. However, there are few reports about $U$. parvum as an invasive organism in neonatal meningitis. Herein, we describe a full-term infant who developed $U$. parvum meningitis complicated with subdural hematoma.

\section{Case presentation}

The male baby in this case was born by spontaneous vaginal delivery (gravida 2 para 2 ) at 40 weeks of gestation with a birth weight $3800 \mathrm{~g}$. The pregnancy was uneventful. Half an hour after birth, the baby was admitted to the neonatal department with moaning and tachypnea. Ampicillin sulbactam was initiated due to the possibility of pneumonia. Laboratory tests showed leukocytosis $\left(17.93-35.3 \times 10^{9} / \mathrm{l}\right)$

(c) The Author(s). 2021 Open Access This article is licensed under a Creative Commons Attribution 4.0 International License, which permits use, sharing, adaptation, distribution and reproduction in any medium or format, as long as you give appropriate credit to the original author(s) and the source, provide a link to the Creative Commons licence, and indicate if changes were made. The images or other third party material in this article are included in the article's Creative Commons licence, unless indicated otherwise in a credit line to the material. If material is not included in the article's Creative Commons licence and your intended use is not permitted by statutory regulation or exceeds the permitted use, you will need to obtain permission directly from the copyright holder. To view a copy of this licence, visit http://creativecommons.org/licenses/by/4.0/ The Creative Commons Public Domain Dedication waiver (http://creativecommons.org/publicdomain/zero/1.0/) applies to the data made available in this article, unless otherwise stated in a credit line to the data. 
and C-reactive protein (CRP: $0.1-11.2 \mathrm{mg} / \mathrm{l})$. Although his symptoms improved, the baby had a fever on day 5 of hospitalization. The antibiotic was changed to cefotaxime, though the baby still had a mild fever on day 9 of hospitalization. Moreover, blood analysis revealed greatly elevated CRP $(47.5 \mathrm{mg} / \mathrm{l})$. MRI revealed right parietal temporal and bilateral occipital subdural hemorrhage, and the baby ( 9 days old) was transferred to our hospital due to subdural hemorrhage.

On admission to our hospital, the baby still had a fever $\left(37.7^{\circ} \mathrm{C}\right)$ with tight fontanel. The disease progressed, and the baby developed seizures. The cerebrospinal fluid (CSF) cell count was 1311/1 (88\% lymphocytes); protein and glucose levels were $1.653 \mathrm{~g} / \mathrm{l}$ and $1.21 \mathrm{mmol} / \mathrm{l}$, respectively. CT scan displayed right parietal temporal hematoma with a midline shift (Fig. 1a). Intravenous empiric treatment for meningitis with cefotaxime and ampicillin was started, as was intracranial pressure relief (glycerol fructose), hemostasis and anticonvulsion therapy. Two days later, subdural hematoma removal and external drainage of the subdural hemorrhage were performed. Four days after the surgery, the baby had a recurrent fever. CSF analysis repetitively revealed pronounced inflammation of bacterial meningitis, as reflected by CSF pleocytosis (1135-1319 leukocytes/ $\mu \mathrm{l}, 60-66 \%$ lymphocytes), CSF protein levels of $1.36-2.259 \mathrm{~g} / \mathrm{l}$ and CSF glucose levels of $0.45-1.21 \mathrm{mmol} / \mathrm{l}$. However, microbial diagnostics, including repetitive culture of the CSF and blood, were not informative. Additionally, PCR for enteroviruses and herpes simplex virus was negative. Because of the recurrence of symptoms, treatment with meropenem and linezolid was started based on the suspicion of resistant bacteria on day 12 of hospitalization. Furthermore, the
CSF was collected and sent for pathogen detection by metagenomic next-generation sequencing (mNGS) (BGI, Shenzhen, China). $U$. parvum was detected, and CSF culture on mycoplasma identification medium (Jiangmen Kailin Trading Co., Ltd., China.) for Ureaplasma spp. was positive. The diagnosis was confirmed as $U$. parvum meningitis. Meropenem and linezolid were discontinued, and intravenous erythromycin $(30 \mathrm{mg} / \mathrm{kg} / \mathrm{d}$ bid) was started. His clinical symptoms improved quickly, and the CSF gradually normalized (Fig. 2). After 36 days, CSF culture was negative for Ureaplasma spp., and mNGS revealed no $U$. parvum in the CSF; thus, erythromycin was stopped. During hospitalization, MRI revealed atrophy of the right cerebral hemisphere with cortical necrosis (Fig. 1b). Ultrasound before discharge showed a slight enlargement of lateral ventricles (body of left lateral ventricle: $0.64 \mathrm{~cm}$; body of right lateral ventricle: $0.60 \mathrm{~cm}$ ). The infant developed well without abnormal neurological signs at the follow-up when he was 5 months old.

\section{Discussion and conclusions}

Ureaplasma belongs to the family Mycoplasmataceae, which is a common opportunistic pathogens of the urogenital tract with a colonization rate of $40-80 \%$. The vertical transmission rate of Ureaplasma may range from 18 to 88\% [5]. Since 2002, human Ureaplasma spp. have been divided into two groups: $U$. parvum (serovars $1,3,6$, and 14 ) and $U$. urealyticum. (serovars $2,4,5$, and 7 to 13) [6]. It is reported that both the prevalence and transmission of $U$. parvum in pregnant women are higher than those of $U$. urealyticum $[7,8]$. Ureaplasma spp. has been associated with adverse neonatal outcomes, but little is known about CNS infection by these

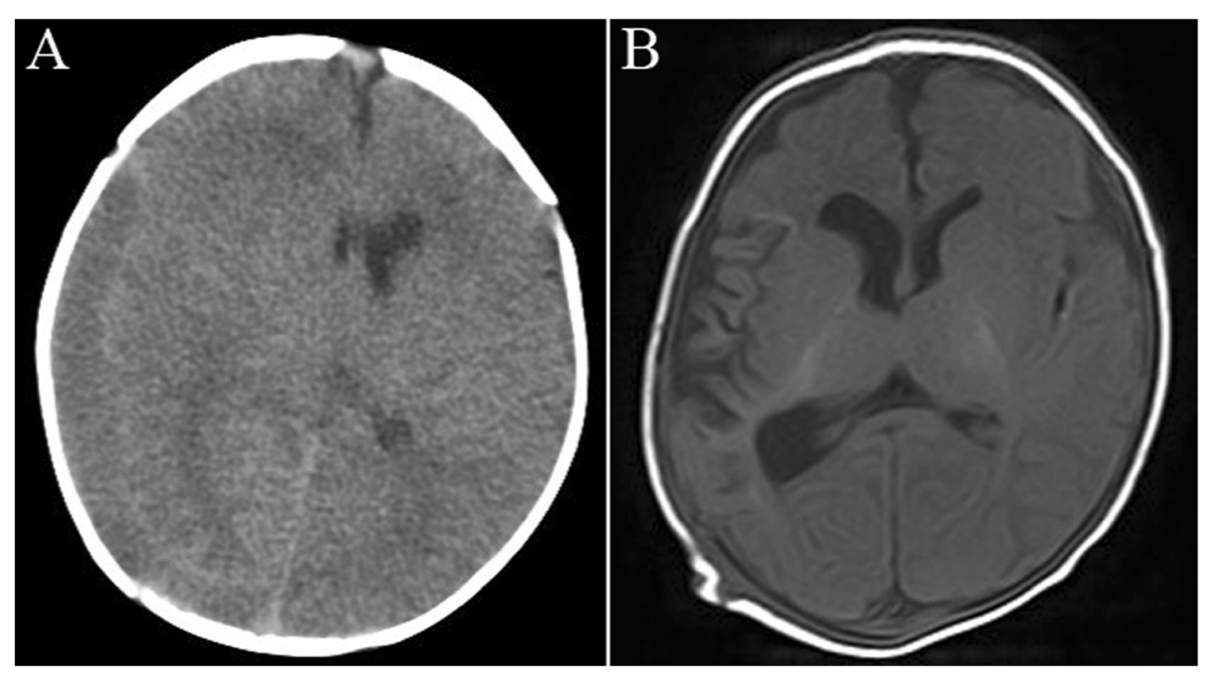

Fig. 1 The change in imaging of the head during hospitalization. CT scan displayed a right parietal temporal hematoma with a midline shift (a). After subdural hematoma removal and external drainage of subdural hemorrhage, MRI revealed atrophy of the right cerebral hemisphere with cortical necrosis and mild dilatation of the third ventricle. No detection of intraventricular hemorrhage was found (b) 


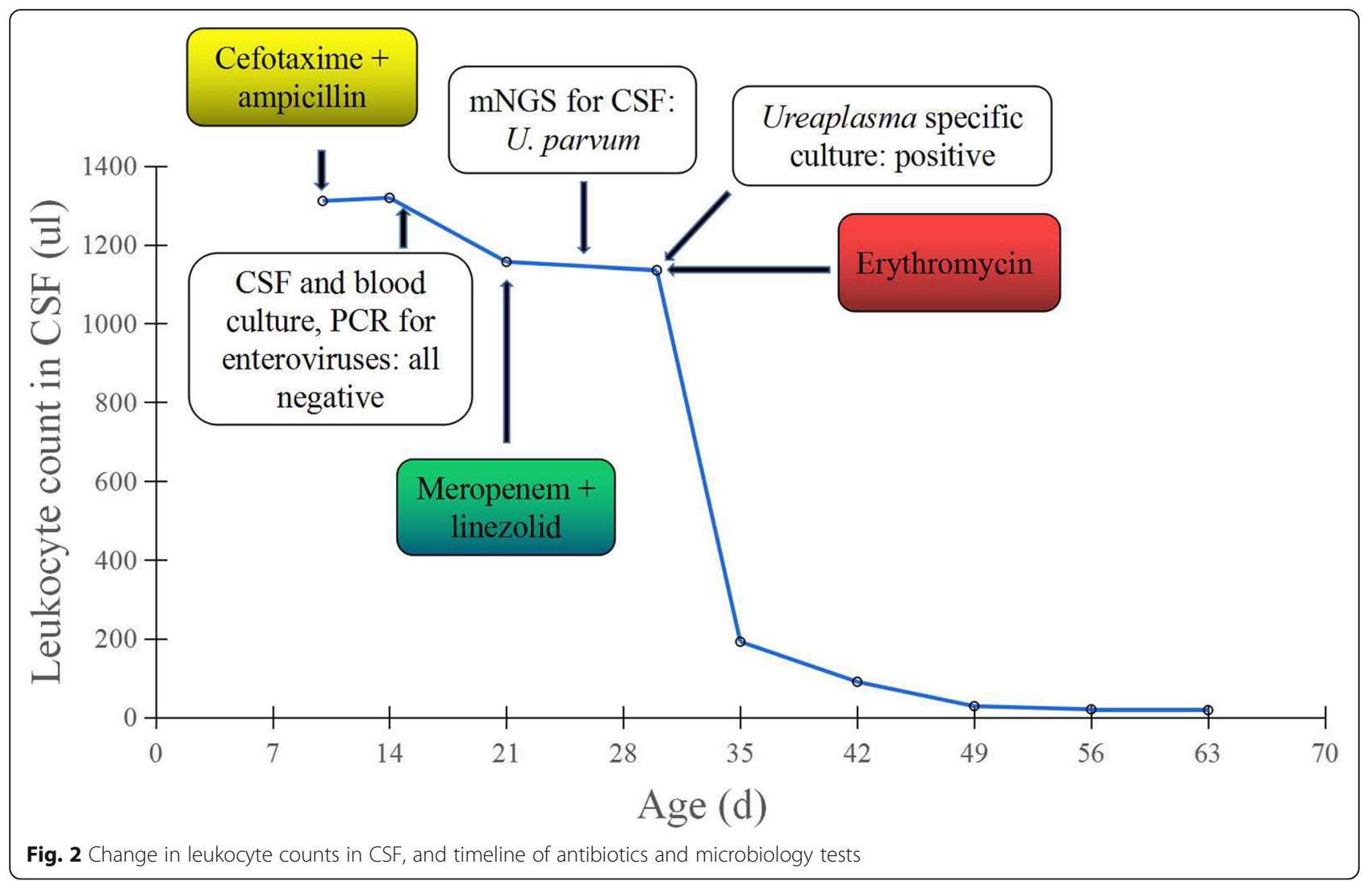

bacteria in neonates. Nonetheless, a growing number of studies have focused on the relationship between Ureaplasma spp. and CNS infection/inflammation $[9,10]$. Some in vitro studies found evidence of Ureaplasma-driven apoptosis in human brain microvascular endothelial cells (HBMECs), which might ultimately result in blood-brain barrier breakdown and CNS inflammation [10].

$U$. parvum meningitis has rarely been reported in neonates. To the best of our knowledge, there are only five case reports of $U$. parvum neonatal meningitis in the English literature (Table 1) [11-15]. The presentation of $U$. parvum CNS infection in neonates is atypical and includes fever, irritability, floppy, seizure, apnea, bradycardia and intraventricular hemorrhage (IVH). The main complications reported are dilatation of the lateral ventricles, IVH (grade I - IV), and subdural hygromas. In particular, ventricular dilation or hydrocephalus was observed in all 6 cases. Three patients underwent ventriculoperitoneal (VP) shunt surgery. This appears to be the first case report of neonatal $U$. parvum CNS infection complicated by subdural hematoma. In addition, CSF changes in Ureaplasma meningitis were characterized by pleocytosis and significantly elevated CSF protein levels and reduced glucose levels (Table 2). Neither the clinical manifestation nor the CSF characteristics of $U$. parvum meningitis differed from those of meningitis due to other bacteria. The diagnosis of $U$. parvum CNS infection is challenging.

Table 1 Basic characteristics of neonatal meningitis caused by U. parvum

\begin{tabular}{|c|c|c|c|c|}
\hline Author, year & Sex/Age (d) & Birth weight (g) & Gestation (weeks) & Presentation/Complication \\
\hline Clifford V et al., 2010 [11] & Female/18 & 1630 & 30 & fever, cardiovascular instability apnea, IVH (III), hydrocephalus \\
\hline Biran V et al., 2010 [12] & NA/10 & 3500 & 39 & fever, rhinitis, conjunctivitis, seizure, dilated ventricles \\
\hline Glaser K et al., 2014 & Female/28 & 946 & $26+3$ & $\begin{array}{l}\text { weak and floppy, generalized muscular hypotonia, lack of } \\
\text { tendon reflexes; hydrocephalus, }\end{array}$ \\
\hline Keus AMJMH et al., 2019 [13] & Male/6 & NA & Full term ${ }^{a}$ & $\begin{array}{l}\text { irritability, fever, seizure, ventricular dilation, ventriculitis, } \\
\text { subdural collections }\end{array}$ \\
\hline Wang Q et al., 2020 [14] & Male/11 & 3390 & 40 & fever, floppy, seizure, hydrocephalus \\
\hline Our case & Male/5 & 3800 & 40 & $\begin{array}{l}\text { fever, seizure, subdural hemorrhage, enlargement of lateral } \\
\text { ventricles }\end{array}$ \\
\hline
\end{tabular}

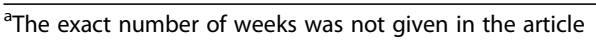




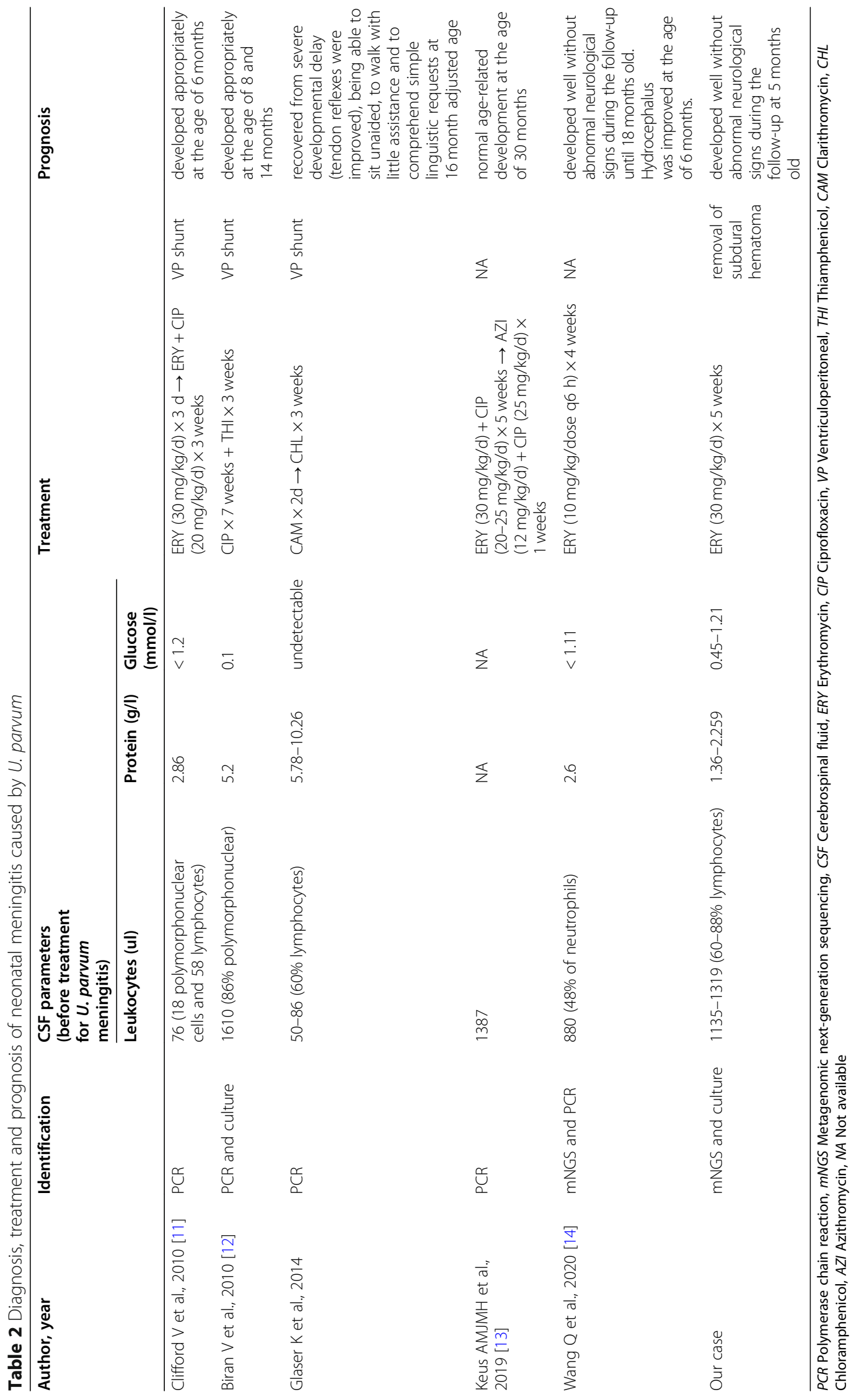


Without a cell wall, Ureaplasma spp. cannot be stained by Gram stain, and microbial diagnosis of Ureaplasma spp. requires special culture. In some labs, there is no special culture media for detecting Ureaplasma spp. in the CSF. Therefore, the diagnosis of Ureaplasma meningitis in neonates might often be delayed. At approximately $90 \%, \mathrm{PCR}$ is considered to be more sensitive than culture for the detection of Ureaplasma spp. [16, 17]. However, in this case, both routine culture and PCR (for enteroviruses and herpes simplex virus) of the CSF were negative. We confirmed the microbe by mNGS, which has been applied as a novel strategy for detecting pathogens causing infectious diseases, especially neurological infections [18].

CSF mNGS is an unbiased approach that can diagnose infections due to viruses (DNA and RNA viruses), parasites, fungi and bacteria in a single test. Moreover, it can identify pathogens that are rare, novel or overlooked. mNGS has a higher sensitivity than culture for pathogens, and mNGS data are increasingly available for diagnosing the pathogen in neurological infections [19]. However, nucleic acid contamination from specimens or the environment might lead to false positives, making it challenging to interpret the results. Furthermore, it is expensive, with costs of approximately US $\$ 2000$ [18]. In China, the cost is approximately US $\$ 600-1000$, which is also more expensive than culture and PCR. In our opinion, mNGS is helpful for diagnosing intracranial infection when routine testing of microbes is negative and the infection is not improved by routine treatment.

The treatment of $U$. parvum infection meningitis in neonates is limited. There is no consensus regarding the choice of antibiotic, dosage, or duration of treatment. It has been reported that macrolides, chloramphenicol, fluoroquinolones and thiamphenicol can be used for $U$. parvum meningitis as either monotherapy or combination therapy (Table 2). Nonetheless, due to the toxicity of chloramphenicol, fluoroquinolones and thiampheni$\mathrm{col}$, the use of these antibiotics is restricted in neonates. Macrolides might represent a recognized treatment option for Ureaplasma. However, macrolide resistance in Ureaplasma spp. has been described in different populations [9, 20, 21]. Moreover, with poor CNS penetrance, macrolide antibiotics, such as erythromycin, might not constitute an effective treatment in the case of $U$. parvum meningitis. Regardless, in our case, Ureaplasma meningitis was improved by a single drug (erythromycin), as in the case reported by Wang Q et al. [14]. Clifford V also found that combined therapy of erythromycin and ciprofloxacin was effective for neonatal $U$. parvum meningitis [12]. Thus, considering the potential side effects of chloramphenicol, fluoroquinolones and thiamphenicol, as based on limited literature, treatment with erythromycin can be started to determine whether combined therapy needs to be implemented. There is no recommendation about the duration of anti-infection therapy for neonatal $U$. parvum meningitis. We treated our patient with erythromycin for approximately 5 weeks. In other cases, the course of therapy ranged from 3 to 7 weeks.

In conclusion, the manifestation of $U$. parvum meningitis might be similar to that of meningitis due to other bacteria in neonates. When a baby does not respond to regular treatment, detection of $U$. parvum in the CSF should be considered as early as possible. mNGS is recommended, which can identify pathogens in a hypothesis-free way and play an increasingly important role in infectious diseases. The treatment of $U$. parvum meningitis in neonates is still a challenge, and further research is needed.

\section{Abbreviations \\ U. Parvum: Ureaplasma parvum; CSF: Cerebrospinal fluid; mNGS: Metagenomic next-generation sequencing; CNS: Central nervous system; IVH: Intraventricular hemorrhage; VP: Ventriculoperitoneal; PCR: Polymerase chain reaction}

\section{Acknowledgements \\ We are thankful to the parents of patient for the support given in providing} the data.

\section{Authors' contributions}

CZ contributed to the study concept, design and drafting of the manuscript. LC contributed to the collection and analysis of the data. LH contributed to the supervision and interpretation of the data. All authors read and approved the final manuscript.

\section{Funding}

No funding was received for this study.

Availability of data and materials

The datasets used and/or analysed during the current study are available from the corresponding author on reasonable request.

\section{Declarations}

Ethics approval and consent to participate

This present study was approved by the Ethics Committee of the Children's Hospital of Zhejiang University School of Medicine.

\section{Consent for publication}

Written informed consent was obtained from the patient's parents for publication of this case report and any accompanying images. A copy of the written consent form is available for review by the Editor-in-Chief of this journal.

\section{Competing interests}

The authors declare that they have no competing interests.

Received: 9 November 2020 Accepted: 8 March 2021

Published online: 17 March 2021

\section{References}

1. Barichello T, Fagundes GD, Generoso JS, Elias SG, Simões LR, Teixeira AL. Pathophysiology of neonatal acute bacterial meningitis. J Med Microbiol. 2013:62(Pt 12):1781-9. https://doi.org/10.1099/jmm.0.059840-0.

2. Gordon SM, Srinivasan L, Harris MC. Neonatal meningitis: overcoming challenges in diagnosis, prognosis, and treatment with Omics. Front Pediatr. 2017;5:139. https://doi.org/10.3389/fped.2017.00139. 
3. Sprong KE, Mabenge M, Wright CA, Govender S. Ureaplasma species and preterm birth: current perspectives. Crit Rev Microbiol. 2020;46(2):169-81. https://doi.org/10.1080/1040841X.2020.1736986.

4. Viscardi RM, Kallapur SG. Role of Ureaplasma respiratory tract colonization in Bronchopulmonary dysplasia pathogenesis: current concepts and update. Clin Perinatol. 2015;42(4):719-38. https://doi.org/10.1016/j.clp.2015.08.003.

5. Waites KB, Katz B, Schelonka RL. Mycoplasmas and ureaplasmas as neonatal pathogens. Clin Microbiol Rev. 2005;18(4):757-89. https://doi.org/10.1128/ CMR.18.4.757-789.2005.

6. Robertson JA, Stemke GW, Davis JW, Harasawa R, Thirkell D, Kong F, Shepard MC, Ford DK. Proposal of Ureaplasma parvum sp. nov. and emended description of Ureaplasma urealyticum (Shepard et al. 1974) Robertson et al. 2001. Int J Syst Evol Microbiol. 2002;52(Pt 2):587-97. https:// doi.org/10.1099/00207713-52-2-587.

7. Peretz A, Tameri O, Azrad M, Barak S, Perlitz Y, Dahoud WA, Ben-Ami M, Kushnir A. Mycoplasma and Ureaplasma carriage in pregnant women: the prevalence of transmission from mother to newborn. BMC Pregnancy Childbirth. 2020;20(1):456. https://doi.org/10.1186/s12884-020-03147-9.

8. Kong F, Ma Z, James G, Gordon S, Gilbert GL. Species identification and subtyping of Ureaplasma parvum and Ureaplasma urealyticum using PCRbased assays. J Clin Microbiol. 2000;38(3):1175-9. https://doi.org/10.1128/ JCM.38.3.1175-1179.2000

9. Glaser K, Speer CP. Neonatal CNS infection and inflammation caused by Ureaplasma species: rare or relevant? Expert Rev Anti-Infect Ther. 2015;13(2): 233-48. https://doi.org/10.1586/14787210.2015.999670.

10. Silwedel C, Haarmann A, Fehrholz M, Claus H, Speer CP, Glaser KJ. More than just inflammation: Ureaplasma species induce apoptosis in human brain microvascular endothelial cells. Neuroinflammation. 2019;16(1):38. https://doi.org/10.1186/s12974-019-1413-8

11. Clifford V, Tebruegge M, Everest N, Curtis N. Ureaplasma: pathogen or passenger in neonatal meningitis? Pediatr Infect Dis J. 2010;29(1):60-4 https://doi.org/10.1097/INF.0b013e3181b21016.

12. Biran V, Dumitrescu AM, Doit C, Gaudin A, Bébéar C, Boutignon H, Bingen E, Baud $\mathrm{O}$, Bonacorsi S, Aujard Y. Ureaplasma parvum meningitis in a full-term newborn. Pediatr Infect Dis J. 2010;29(12):1154. https://doi.org/10.1097/INF. Ob013e3181f69013.

13. Keus AMJMH, Peeters DD, Bekker W, Veldkamp KEKE, Lambregts MM, BoltWieringa JJ, et al. Neonatal meningitis and subdural empyema caused by an unusual pathogen. Pediatr Infect Dis J. 2019;38(12):e329-31. https://doi. org/10.1097/INF.0000000000002482.

14. Wang Q, Wang K, Zhang Y, Lu C, Yan Y, Huang X, Zhou J, Chen L, Wang D. Neonatal Ureaplasma parvum meningitis: a case report and literature review. Transl Pediatr. 2020;9(2):174-9. https://doi.org/10.21037/tp.2020.02.04.

15. Glaser K, Wohlleben M, Speer CP. An 8-month history of meningitis in an extremely low birth weight infant? - long-lasting infection with Ureaplasma parvum. Z Geburtshilfe Neonatol. 2015;219(1):52-6. https://doi.org/10.1055/ s-0034-1395537.

16. Waites KB, Xiao L, Paralanov V, Viscardi RM, Glass Jl. Molecular methods for the detection of mycoplasma and ureaplasma infections in humans: a paper from the 2011 William Beaumont Hospital symposium on molecular pathology. J Mol Diagn. 2012;14(5):437-50. https://doi.org/10.1016/j.jmoldx.2012.06.001.

17. Cao X, Wang $Y$, Hu X, Qing H, Wang H. Real-time TaqMan polymerase chain reaction assays for quantitative detection and differentiation of Ureaplasma urealyticum and Ureaplasma parvum. Diagn Microbiol Infect Dis. 2007;57(4): 373-8. https://doi.org/10.1016/j.diagmicrobio.2006.09.006.

18. Ramachandran PS, Wilson MR. Metagenomics for neurological infections expanding our imagination. Nat Rev Neurol. 2020;13:1-10.

19. Miao Q, Ma Y, Wang Q, Pan J, Zhang Y, Jin W, et al. Microbiological Diagnostic Performance of Metagenomic Next-generation Sequencing When Applied to Clinical Practice. Clin Infect Dis. 2018;67(suppl_2):S231-40.

20. Chung HY, Chung JW, Chun SH, Sung HS, Kim MN, Kim KS. A case of erythromycin-resistant Ureaplasma urealyticum meningitis in a premature infant. Korean J Lab Med. 2007;27(1):46-9. https://doi.org/10.3343/kjlm.2 007.27.1.46.

21. Beeton ML, Spiller OB. Antibiotic resistance among Ureaplasma spp. isolates: cause for concern? J Antimicrob Chemother. 2017;72(2):330-7. https://doi. org/10.1093/jac/dkw425.

\section{Publisher's Note}

Springer Nature remains neutral with regard to jurisdictional claims in published maps and institutional affiliations.

Ready to submit your research? Choose BMC and benefit from:

- fast, convenient online submission

- thorough peer review by experienced researchers in your field

- rapid publication on acceptance

- support for research data, including large and complex data types

- gold Open Access which fosters wider collaboration and increased citations

- maximum visibility for your research: over $100 \mathrm{M}$ website views per year

At BMC, research is always in progress.

Learn more biomedcentral.com/submissions 